\section{Preliminary evaluation of the "Dengue-MI" technology for Aedes aegypti monitoring and control}

\author{
Avaliação preliminar da tecnologia "MI-Dengue" \\ para o monitoramento e controle \\ do Aedes aegypti
}

\section{${ }^{1}$ Instituto de Ciências Biológicas, Universidade Federal de Minas Gerais, Belo Horizonte, Brasil. 2 Fundação Nacional de Saúde, Belo Horizonte, Brasil. \\ Correspondence A. E. Eiras \\ Laboratório de Ecologia Química de Vetores, Departamento de Parasitologia, Instituto de Ciências Biológicas, Universidade Federal de Minas Gerais. Av. Presidente Antônio Carlos 6627, Belo Horizonte, $M G$ 31270-901, Brasil. alvaro@icb.ufmg.br}

\begin{abstract}
Limitations in the laboratory identification of Aedes aegypti and processing of field data based on larval surveys led to the development of the "Intelligent Dengue Monitoring" technology (MI-Dengue). MI-Dengue consists of a trap that captures gravid female Ae. aegypti, coupled with a computerized system for field data collection, transmission, and access to georeferenced maps in real time. The current study describe the first experience with a system for monitoring adult Ae. aegypti and presents the preliminary results in three municipalities that adopted MI-Dengue as a strategy to identify key areas and orient control measures. Weekly georeferenced maps and an entomological indicator (Mean Female Aedes Index) provided information on infested areas and infestation levels, color-coded according to the number of captured female Ae. aegypti, and indicated risk-free, dengue alert, and critical situations that triggered appropriate control measures. The preliminary results suggest that the adoption of this control strategy with house-tohouse visits in a $200 \mathrm{~m}$ radius of the positive trap helped reduce dengue in the municipalities that adopted the system.
\end{abstract}

Dengue; Vector Control; Monitoring; Spatial Analysis
Álvaro Eduardo Eiras 1

Marcelo Carvalho Resende 1,2

\section{Introduction}

The only measure currently available to block the dengue transmission chain is to control the $\mathrm{Ae}$ des aegypti vector. Given the persistent difficulties in attempts to control Ae. aegypti, the use of an active entomological surveillance system for early vector detection would allow implementing immediate control measures with the aim of reducing Ae. aegypti infestation and thus the risk of dengue occurrence ${ }^{1,2}$.

In Brazil, Ae. aegypti is monitored by larval surveys 3 , a bimonthly method with low sensitivity that uses intensive field and laboratory labor. The method provides unreliable dengue risk rates, since it utilizes entomological indices based on immature forms of the vector, whereas methods that capture adult mosquitoes furnish more adequate indices for dengue control programs $4,5,6$.

Ovitraps baited with grass infusions are more sensitive than larval surveys $4,5,7,8$, but their use is indicated more for periods of low vector population density. The method also requires laboratory personnel and only allows quantifying the number of eggs deposited, thus hindering estimation of the vector population density in a given area 4 . The backpack aspirator 9 and Nasci aspirator 10 have been used to capture resting adult Ae. aegypti, mainly outdoors, but with limitations, especially because the method is laborintensive and intrusive. 
The MosquiTRAP (Ecovec Ltda., Belo Horizonte, Brazil) was developed on the basis of detailed behavior studies on oviposition by female Ae. aegypti when they enter ovitraps. The MosquiTRAP captures adult mosquitoes, especially gravid females, but rarely parous and nulliparous specimens 11 , due to the use of a synthetic oviposition attractant (AtrAedes, Ecovec Ltda., Belo Horizonte, Brazil) developed from volatile grass infusions. The mosquitoes are captured by a sticky card, where they initially remain stuck by their legs, generally staying in the resting position, and when they are still alive on the card, they beat their wings in an attempt to escape. When dead, the specimens stick to the card sideways and are easily identified because this lateral position allows visualizing the essential characters. An important advantage of MosquiTRAP is that it identifies the insect during field inspection of the trap, avoiding the expenditure of laboratory personnel, equipment, and time to identify the mosquitoes, thus saving labor and infrastructure costs.

The ideal place to set the MosquiTRAP in households is in the outdoor environment (e.g., front or back yard), probably since the females take their blood meals indoors and lay eggs outdoors 11. Field studies have shown that the MosquiTRAP is more sensitive than larval surveys and less sensitive than ovitraps, and that it allows detecting and monitoring Ae. aegypti throughout the year. Studies in Belo Horizonte, Minas Gerais demonstrated that MosquiTRAP is capable of detecting and monitoring female Ae. aegypti even during the dry season, when larval surveys do not detect the presence of larvae 8 . When compared to other methods for capturing adult mosquitoes, like the CDC backpack aspirator (Model 1412, John W. Hock Company, Gainesville, USA) 12, the latter captured significantly fewer gravid females than the MosquiTRAP, whereas the Nasci captured a similar number 9 .

Georeferenced information systems have been used to locate infestations of Ae. aegypti larvae 13,14,15,16 and eggs 17,18 in urban areas. The field data collected by larval surveys, ovitraps, and the Nasci aspirator are recorded on printed spreadsheets, usually attached to a clipboard by field inspectors. The data are later keyed in and consolidated on the computer. Observation of the difficulties involved in these field procedures motivated the development of the Intelligent Dengue Monitoring system (MI-Dengue, Ecovec Ltda., Belo Horizonte, Brazil), consisting of a set of tools that allow capturing and identifying the adult vector with the MosquiTRAP, recording and sending data on electronic spreadsheets, and providing entomological indices and georefer- enced maps on infestations of female Ae. aegypti, on-line on the Internet, to orient vector control activities by municipal health managers.

The current study aims to describe, for the first time, a pioneering system for monitoring gravid female Ae. aegypti and to show the preliminary results in the municipalities (counties) of Três Lagoas (Mato Grosso do Sul State) and Bastos and Presidente Epitácio (São Paulo State) that adopted the information provided by MI-Dengue as a strategy to identify and orient dengue vector control activities.

\section{Materials and methods}

\section{MosquiTRAP}

MosquiTRAP consists of a matte black container (33cm high by $15 \mathrm{~cm}$ wide), divided into two parts: a lower base, filled with approximately 300 $\mathrm{ml}$ of tap water, and an upper part with a funnelshaped opening, facilitating the mosquito's entry and hindering its exit. An odorless sticky card that holds the captured mosquitoes is attached from the water line in the lower base to the upper part of the trap. The device that releases the synthetic oviposition attractant (AtrAedes) was attached to the sticky card. The traps were attached in a visible place, at a maximum height of $1.5 \mathrm{~m}$ above ground, sheltered from sun and rain, out of reach of domestic animals and children. During trap inspection, the captured mosquitoes were identified using a magnifying glass (20x), recorded, and removed from the sticky card. The captured mosquitoes were either discarded or stored monthly in plastic tubes and sent to the Chemical Ecology and Insect Vector Laboratory of Universidade Federal de Minas Gerais (UFMG) to review that percentage of correct species identification. The minimum standard for correct identification by field inspectors was $95 \%$, and whenever the rate dropped below this level the inspector was retrained in the identification of genera (Culex and Aedes) and species (Ae. aegypti and Ae. albopictus). The sticky card was changed every 30 days and the AtrAedes attractant every 45 days, whereas the water was changed weekly.

\section{Computerized System for Intelligent Dengue Monitoring (MI-Dengue)}

The system consists of recording field data from the MosquiTRAP with an electronic spreadsheet and specific software (Geo-Dengue, Ecovec Ltda, Belo Horizonte, Brazil). This system allows sending and making data available online on the Internet for municipal health managers to access 
and view information on the density of gravid female Ae. aegypti on georeferenced maps and in analytical tables of the sites monitored with MosquiTRAP. The MI-Dengue computerized system consists of three software programs developed to streamline information: (a) geo-dengue collection: installed in portable devices (e.g., palmtops or cell phones) to record Ae. aegypti field capture data; (b) geo-dengue monitoring: processes the field data and automatically produces tables with entomological indices and graphs with trends for analysis; and (c) geo-dengue: produces georeferenced maps of mosquitoes captured with MosquiTRAP and makes them available to users on the Internet, according to epidemiological week.

\section{Data acquisition on electronic spreadsheets}

The data were acquired daily during trap inspection by means of an electronic spreadsheet installed in palmtop computers (Model 515, Palmtop, USA), using the Geo-Dengue program. These data were transferred automatically to the municipality's database, and the site automatically generated the georeferenced maps and tables for the municipal manager (only the entomological indices were provided weekly). The electronic spreadsheet allowed recording the household data (e.g., resident's name, address, ZIP code, and place where trap was installed in the residence), data on adult mosquitoes captured and their respective numbers per trap installed in the residences for each block in the monitored municipalities, thus facilitating the work by the field inspector during trap inspection. Field inspectors were trained to identify the mosquitoes captured in the MosquiTRAP with the aid of a field magnifying glass (20x), where they generally identified Ae. aegypti and Ae. albopictus by species and sex, recorded the number of specimens captured on the electronic spreadsheet, while for mosquitoes from genus Culex and other Aedes (non-aegypti) they only recorded the information by genus.

\section{Implementation of MI-Dengue in the municipality}

The methodology was implemented in the entire urban area of the three municipalities. After a geographic survey of each city, the traps were set outside residences and the geographic coordinates were recorded by means of a Global Position System (GPS), with a density of 16 traps per $\mathrm{km}^{2}$, corresponding to an average of one trap per set of four to six blocks. This density was determined on the basis of studies performed in Mirassol (São Paulo) 11, using the databank that was analyzed by random sampling without re- placement in the R software (The R Foundation for Statistical Computing, Vienna, Austria; http:// www.r-project.org).

Each municipality had a technical team from the Municipal Health Secretariat, consisting of: (a) a municipal coordinator, designated as responsible for direct supervision of the work and logistic backup for the field activities; (b) an overall field supervisor, the technician in charge of monitoring all the stages in the fieldwork, including sending the trap inspection data; (c) field inspectors; (d) a vehicle to accompany the field activities, as needed; (e) a focal point near the monitoring area to facilitate the field inspectors' work. Implementation of MI-Dengue in the municipalities did not require any additional human resources, beyond the existing dengue control teams.

The technical team in each municipality received training on MI-Dengue operations, identification of genus/species and sex of the captured mosquitoes, data acquisition on the electronic spreadsheet, data transmission, and access to the results. The Municipal Health Secretariats in each municipality received a password for Internet access to the tables, graphs, and geoprocessed maps that were updated weekly with the trap inspection field data. The health managers were thus able to monitor the positive sites and Ae. aegypti infestation levels.

\section{Situations analyzed in the study and characterization of the municipalities}

Three study groups were used, and three municipalities were selected for each group. Table 1 shows the characteristics of the selected municipalities.

- Study 1: Municipalities that partially adopted MI-Dengue. This group adopted the MI-Dengue system, but did not trigger control measures based on the georeferenced maps. MI-Dengue was implemented in three municipalities in the State of Minas Gerais (Divinópolis, Pará de Minas, and Santa Luzia) for weekly monitoring of gravid female Ae. aegypti. The State and Municipal health managers did not orient control measures to the "dengue alert" and "critical" areas diagnosed by MI-Dengue. The municipalities adopted the methodology based on comprehensive treatments of neighborhoods according to guidelines in the manual published by the National Dengue Control Program 19.

- Study 2: municipalities that adopted MIDengue in full. The municipalities of Três Lagoas (Mato Grosso do Sul State) and Presidente Epitácio and Bastos (São Paulo State) used the weekly data from MI-Dengue to target their con- 
Characterization of study groups and municipalities analyzed in current study of the MI-Dengue system, Brazil.

\begin{tabular}{|c|c|c|c|c|c|c|c|}
\hline \multirow[t]{2}{*}{ Group of cities } & \multicolumn{2}{|c|}{ Data on Municipalities } & \multicolumn{5}{|c|}{ MI-Dengue } \\
\hline & Municipality/State & Population & $\begin{array}{c}\text { Urban } \\
\text { area }\left(\mathrm{km}^{2}\right)\end{array}$ & $\begin{array}{c}\text { Urban area } \\
\text { monitored } \\
\left(\mathrm{km}^{2}\right)\end{array}$ & $\begin{array}{l}\text { Total blocks in } \\
\text { Municipality }\end{array}$ & $\begin{array}{c}\text { Total } \\
\text { traps set }\end{array}$ & $\begin{array}{l}\text { Monitoring } \\
\text { (EW-Year) }\end{array}$ \\
\hline \multirow[t]{3}{*}{ Partially adopted MI-Dengue } & Divinópolis/MG & 207,983 & 46.00 & 46.13 & 5,374 & 738 & 42 (2007)-11 (2008) \\
\hline & Pará de Minas/MG & 80,409 & 21.00 & 20.88 & 1,345 & 334 & 40 (2007)-08 (2008) \\
\hline & Santa Luzia/MG & 214,398 & 40.00 & 14.44 & 1,166 & 231 & 49 (2007)-19 (2008) \\
\hline \multirow[t]{3}{*}{ Adopted MI-Dengue in full } & Três Lagoas/MS & 85,376 & 30.30 & 19.06 & 2,311 & 305 & 17 (2007)-19 (2008) \\
\hline & Presidente Epitácio/SP & 41,580 & 10.95 & 10.95 & 936 & 182 & 11 (2007)-19 (2008) \\
\hline & Bastos/SP & 21,343 & 3.13 & 3.13 & 369 & 100 & 26 (2007)-19 (2008) \\
\hline Did not adopt MI-Dengue & Andradina/SP & 54,794 & 13.53 & - & - & - & - \\
\hline \multirow[t]{2}{*}{ (used larval surveys) } & Presidente Venceslau/SP & 37,155 & 7.77 & - & - & - & - \\
\hline & Rancharia/SP & 23,337 & 5.02 & - & - & - & - \\
\hline
\end{tabular}

EW: epidemiological week; MI-Dengue: Intelligent dengue monitoring; MG: Minas Gerais State; MS: Mato Grosso do Sul State; SP: São Paulo State.

trol measures, as described in the item on vector control measures. This methodology was implemented in Presidente Epitácio on April 28, 2007, Três Lagoas on May 2, 2007, and Bastos on June 23, 2007.

- Study 3: Municipalities that did not adopt MIDengue. The municipalities in this category used larval surveys according to the methodology recommended by the National Dengue Control Program. The cities of Presidente Venceslau, Andradina, and Rancharia (São Paulo State) were selected for comparison with the three municipalities from Study 2, since they have similar characteristics in terms of human population and dengue history since 2006, and the maximum distance between them is $40 \mathrm{~km}$.

\section{Study parameters}

- Mean Female Aedes Index (MFAI): this index was used for weekly monitoring of vector infestations in the neighborhoods and municipalities. MFAI $(M F A I=k / n)$ is the mean number $(k)$ of female Ae. aegypti specimens captured by (n) traps installed per epidemiological week.

- Temporal Mean Female Aedes Index (MFAIt): This index averages the MFAI values for the three previous and consecutive weeks, based on the following formula:

MFAlt $=\frac{\text { MFAl } l_{\text {week }-2}+\text { MFAl }_{\text {week }-1}+\text { MFAl }}{3}$

Where $\mathrm{MFAI}_{\text {week -2 }}$ is the MFAI index for the two previous weeks, MFAI $_{\text {week - } 1}$ for the previous week, and MFAI ${ }_{\text {week } 0}$ is the index for the week being analyzed.

\section{Geoprocessing of infestations with female adult Ae. aegypti}

Two different ways of georeferencing infestations were developed:

- Weekly monitoring of Ae. aegypti infestation in the blocks: weekly monitoring in the blocks as a function of the number of female Ae. aegypti captured by the installed traps was used to establish color categories for classifying blocks as follows: green (absence of captures), yellow (one female $A$. aegypti/MosquiTRAP/week = low infestation), orange (two females $/$ trap $/$ week $=\mathrm{me}$ dium infestation), and red ( $>$ three females/trap/ week $=$ high infestation). These parameters were based on studies by Ritchie et al. 6 showing that in Australia, more than two gravid female Ae. aegyp$t i /$ trap/week was associated with risk of dengue cases.

- Monitoring reinfestation of blocks: used three variables: recurrence of positive traps (female Ae. aegypti captured), time (chronological order of the week in which the capture occurred), and number of female Ae. aegypti in the traps during the previous four weeks in the monitored blocks. The same color-coding was used for the blocks: green (no recurrence), yellow (one female $A e$. aegypti/MosquiTRAP/week = low infestation), orange (two females/trap/week = medium infestation), and red ( $>$ three females/trap/week = high infestation).

Monthly monitoring of Ae. aegypti reinfestation in neighborhoods: Traps were classified by group according to the MFAI in the previous four epidemiological weeks, using the variables (1) 
MFAIt by neighborhood and (2) time (chronological order by epidemiological week). Neighborhoods were color-coded as follows: green (MFAIt $<0.2)$, yellow $(0.2<$ MFAIt $<0.4)$, and red (MFAIt $>$ 0.4 ). This entomological index was based on correlations between the number of dengue cases and the MFAI entomological index in the neighborhood of Jabour, Vitória (Espírito Santo State), where clusters of dengue cases and mosquitoes were observed. The value set for risk of dengue occurrence was MFAIt $\geq 0.4$, while dengue alerts were issued when MFAIt ranged between 0.20 and 0.39 . The situation was considered "risk-free" in terms of dengue when MFAIt $<0.2$ (data not published).

Dengue cases: the number of autochthonous dengue cases reported by each municipality was obtained from the National Disease Notification System (SINAN - http://dtr2004.saude. gov.br/sinamweb/novo) beginning in 2006, to determine the history of dengue cases and allow a comparative analysis of the methodologies implemented by each group.

Vector control measures: the municipalities monitored by MI-Dengue adopted the weekly maps and tables on Ae. aegypti infestation to orient their vector control measures. The activities were those recommended by the National Dengue Control Program (e.g., elimination of breeding sites, tires, and disposables, covering water tanks with lids, use of larvicides, and no use of adulticides), but the only strategy that was added was rapid access to the weekly and monthly data provided on the Internet for dengue alert and critical areas. The control strategy was based on intervention in dengue alert and critical situations in areas with high weekly infestation ( $>$ three females $=$ code red) and monthly monitoring that indicated reinfested areas. The field inspectors adopted control measures with houseto-house visits in a $200 \mathrm{~m}$ radius, or $100 \mathrm{~m}$ on each side of the positive traps, i.e., approximately nine blocks.

Statistical analysis: the number of autochthonous dengue cases reported by each municipality was provided by the SINAN system and the human population by the Brazilian Institute of Geography and Statistics (IBGE), or National Census Bureau. Three comparative clusters were formed, each containing three municipalities (the first with the cities that partially adopted MI-Dengue, the second with those that adopted MI-Dengue in full, and the third with those that used larval surveys, according to National Dengue Control Program guidelines). Analysis of variance (ANOVA) was performed to compare the clusters, within the same year or semester, to verify the difference between mean dengue cas- es. This analysis of autochthonous dengue cases within each period began in 2006, the year that allowed detecting that the municipalities showed the same baseline epidemiological situation. For 2007 and 2008, the analyses were separated by semester, analyzing the incidence trends in autochthonous dengue cases in the three groups.

\section{Results}

\section{Mean Female Aedes Index (MFAl)}

Based on our observations, the MosquiTRAP succeeded in detecting and monitoring the presence of female Ae. aegypti throughout the year (Figure 1). In Três Lagoas, in 52 weeks of monitoring, a total of 14,708 trap inspections were performed, and a total of 2,057 female Ae. aegypti were captured. During monitoring, the lowest MFAI (0.02) occurred in week 22 (July 2007), the season of the year with low rainfall and low temperatures ("winter"), while the highest entomological index (0.43) was recorded in week 11 (March 2008), the season with abundant rainfall and high temperatures ("summer" - Figure 1a).

In Bastos, a total of 2,744 trap inspections were performed and 272 female Ae. aegypti. were captured. The MFAI remained low, between 0.01 and 0.02 , from weeks 28 (July 2007) to 46 (November 2007). From that week on, the MFAI showed a linear growth trend, reaching a peak of 0.59 during epidemiological week 11 (March 2008) (Figure 1b).

In Presidente Epitácio, a total of 2,409 female Ae. aegypti were captured in 9,846 trap inspections during 55 weeks of monitoring. The lowest MFAI (0.03) was in epidemiological week 23 (June 2007) and the highest (0.84) in week 6 (February 2008), during the dry and rainy seasons, respectively (Figure 1c).

\section{Monitoring of block infestations with female} Ae. aegypti using geoprocessing

Every week, by epidemiological week, block-byblock georeferenced maps of infestations with female Ae. aegypti in the municipalities were made available to Municipal Health Secretariats on the Internet. The website provided a window allowing access to all the monitored epidemiological weeks, thus furnishing a spatial and temporal understanding of the infestations. The black dots on the maps represent the blocks where the traps were set. Users clicked on these dots (traps) to access the georeferenced information (latitude and longitude), household address, block and neighborhood numbers, and number of 
Figure 1

Weekly monitoring of Mean Female Aedes Index (MFAl) furnished by MI-Dengue in three municipalities in 2007 and 2008.

1a) Três Lagoas, Mato Grosso do Sul State.

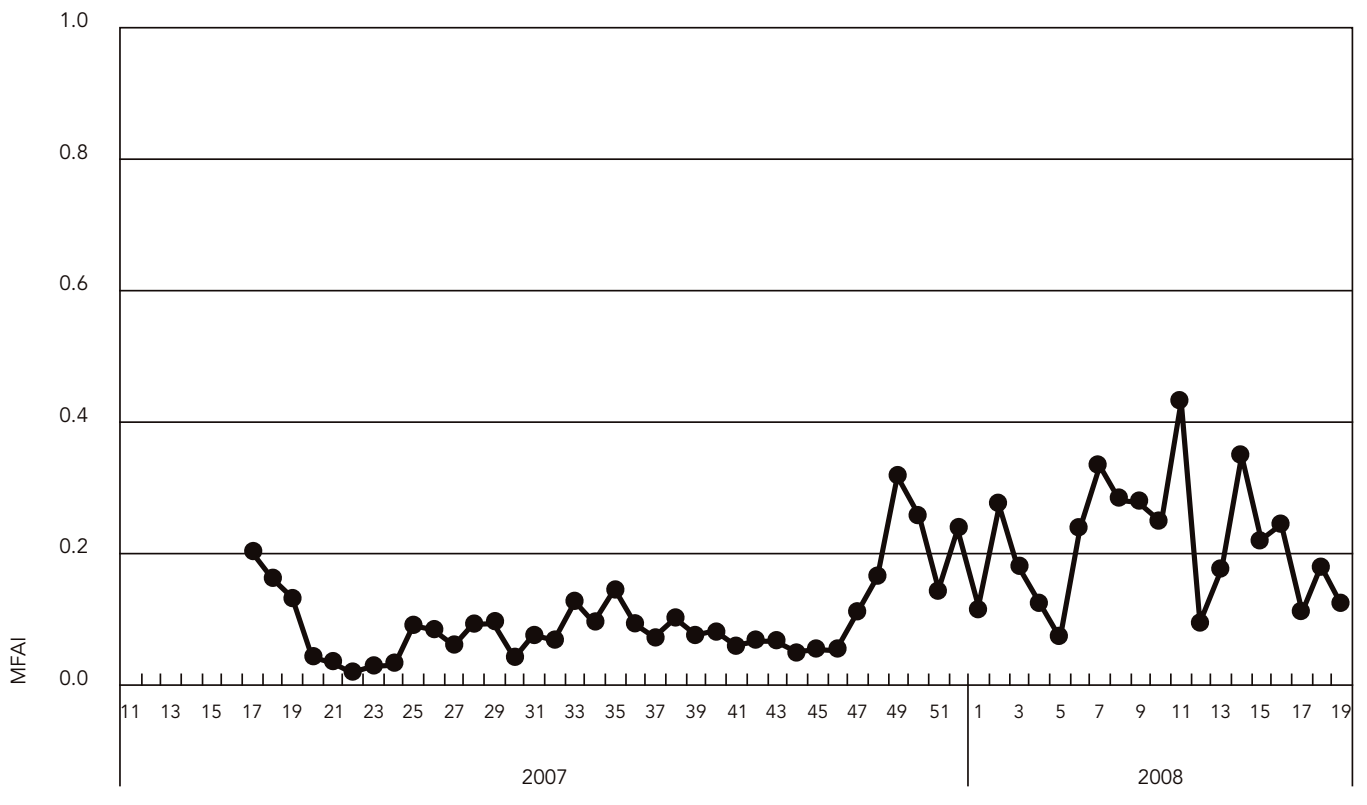

Epidemiological week

1b) Bastos, São Paulo State.

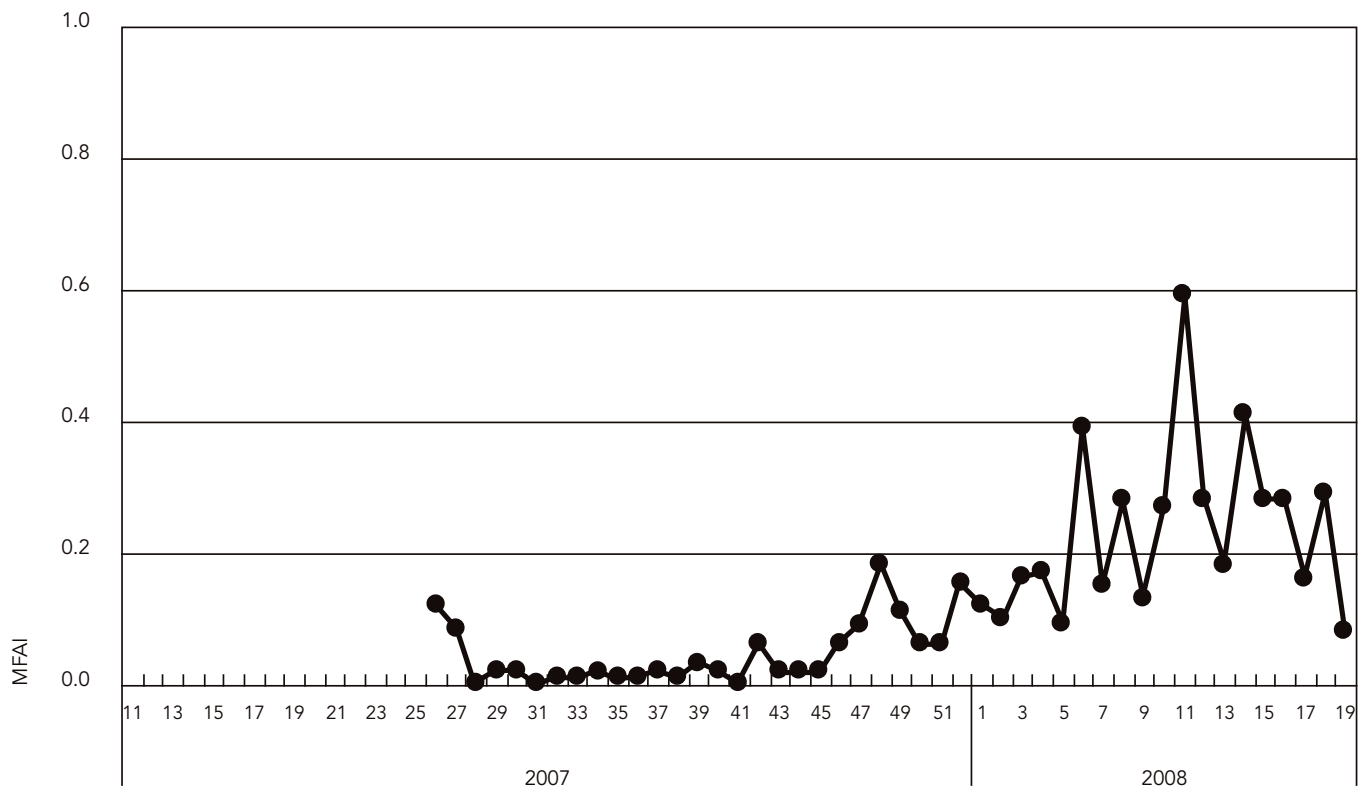

Epidemiological week 
1c) Presidente Epitácio, São Paulo State.

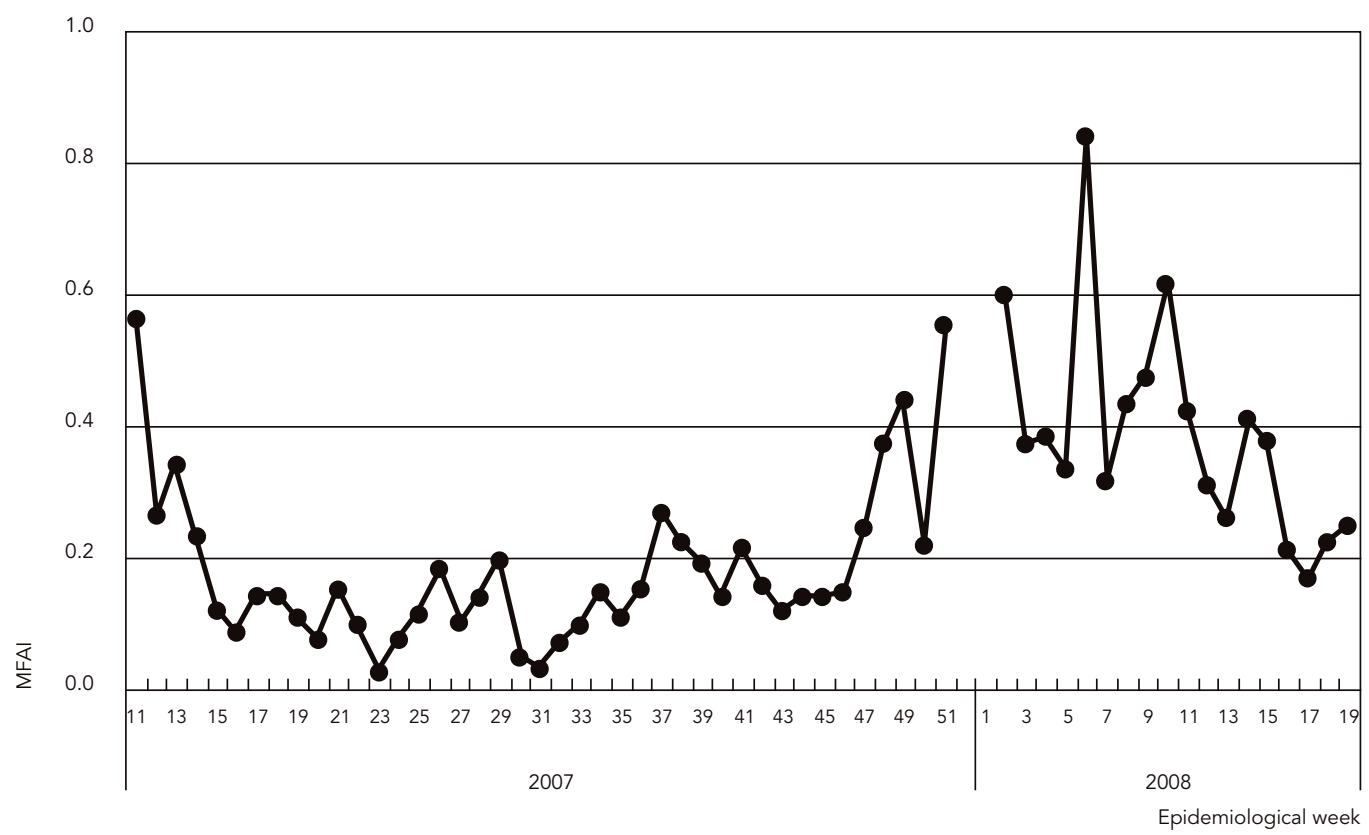

mosquitoes captured during that epidemiological week. The georeferenced maps by epidemiological week provided color-coded information on the sites (blocks) and infestation levels, based on the number of female Ae. aegypti captured in each block (Figure 2). Based on the observations, each week the infested sites were concentrated in given areas or neighborhoods of the municipalities, thus facilitating implementation of targeted control measures.

Monthly monitoring of Ae. aegypti reinfestation in the neighborhoods

In the municipality of Presidente Epitácio, there was a drop in indices after seven weeks of monitoring, as observed in the maps and represented by the shift from categories "dengue alert" and "critical" (epidemiological weeks 7 to 10) to "risk free" and "dengue alert" (epidemiological weeks 14 to 17 ) (Figure 3). Table 2 represents the percentages of neighborhoods in the municipality of Presidente Epitácio classified according to the MFAIt from epidemiological week 7 to 17 . From epidemiological week 7 to 10 there were $44 \%$ and $55 \%$ of neighborhoods classified as "den- gue alert" and "critical", respectively. The MFAIt from epidemiological week 14 to 17 classified the neighborhoods in Presidente Epitácio with $88.9 \%$ and $11.1 \%$ of the municipality's territory as "risk-free" and "dengue alert", respectively, indicating a strong seasonal variation in the Ae. aegypti population density that was probably influenced by the climate conditions or targeted control measures.

\section{Situations analyzed in the dengue control programs}

The activities of the National Dengue Control Program were conducted in all the municipalities and the numbers of cycles were similar for 2007 and 2008 (Table 3). All the municipalities analyzed showed an increase in the total number of cases and dengue incidence in 2006 and 2007 (Table 3), while there was a reduction in the first semester of 2008 in comparison to the first semester of 2007, except for the municipalities of Santa Luzia and Pará de Minas (Minas Gerais State).

Comparing the first semester of 2007 and the second semester of 2007 , the groups of munici- 
Geographic distribution of traps (black dots on map) in the Municipality of Presidente Epitácio (São Paulo State, Brazil) and infestation level by monitored block, color-coded by number of gravid female Aedes aegypti captured (green, yellow, orange, and red). Open window shows epidemiological week 11. See text for details.

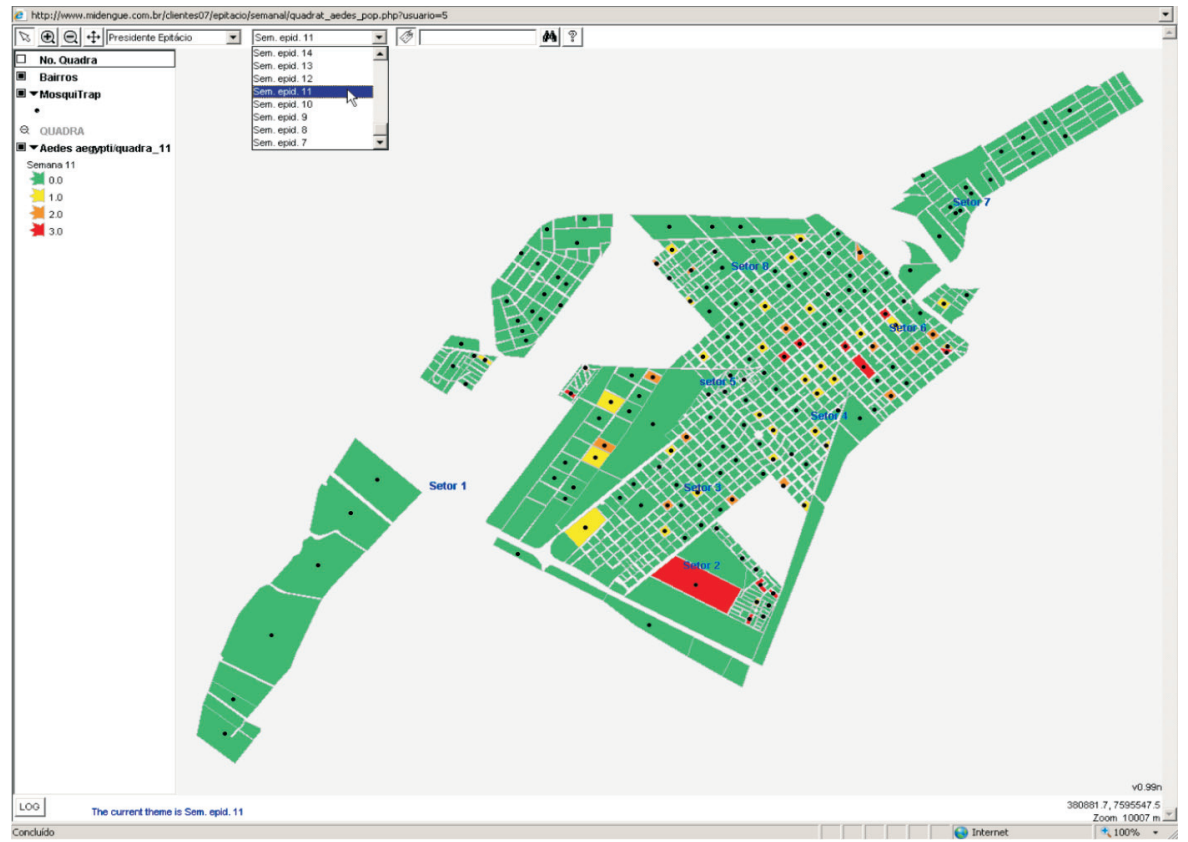

palities that partially adopted MI-Dengue (Study Group 1) and adopted only larval surveys (Study Group 3) reduced dengue incidence by $72 \%$ and $91.4 \%$, respectively, while the group that used the MI-Dengue system in full (Study Group 2) to orient their control activities reduced incidence by $98.9 \%$.

Comparing the first semester of 2007 and the first semester of 2008, the three municipalities that used larval surveys (Andradina, Presidente Venceslau, and Rancharia) reduced dengue incidence by $83 \%$ (Table 3), while those that partially implemented the MI-Dengue system (without using the data to orient their control activities) showed an increase of $51.4 \%$ in dengue incidence (Divinópolis, Santa Luzia, and Pará de Minas). Meanwhile, the municipalities of Três Lagoas, Presidente Epitácio, and Bastos used MI-Dengue to target their control activities and reduced dengue incidence by $93.7 \%$ (Table 3 ).

The incidence of dengue cases was analyzed by comparing two clusters, the first represented by the cities that adopted MI-Dengue and the second by municipalities that used larval surveys, where analysis of variance (ANOVA) failed to detect a significant difference $(\mathrm{F}=0.65$ and $\mathrm{F}=0.05$, respectively, $\mathrm{p}>0.05$ ) between dengue incidence in 2006 and the first semester of 2007. However, ANOVA detected a significant difference in dengue incidence between clusters within the second semester of 2007 ( $F=8.42 ; \mathrm{p}<0.05)$ and the first semester of $2008(\mathrm{~F}=5.13 ; \mathrm{p}<0.05)$.

\section{Discussion}

MosquiTRAP has advantages over other methods for monitoring Ae. aegypti mosquitoes. Since the ideal place for setting the MosquiTRAP in households is outdoors (in the peridomicile) 11, the trap is a non-invasive method ${ }^{9}$, i.e., the field inspector does not have to enter peoples homes, thus facilitating its use for monitoring. Since MosquiTRAP allows identifying the mosquito captured in the trap, without requiring additional procedures in the laboratory, the data collected in the field reaches the health system manager virtually in real time. 
Geoprocessing (infestation analysis) of monitoring of gravid female Aedes aegypti during previous four epidemiological weeks (EW) by neighborhoods in the Municipality of Presidente Epitácio (São Paulo State, Brazil) in 2007. Green represents "risk-free (non-critical)", yellow represents "dengue alert", and red "critical".

3a) Epidemiological week 7 to 10

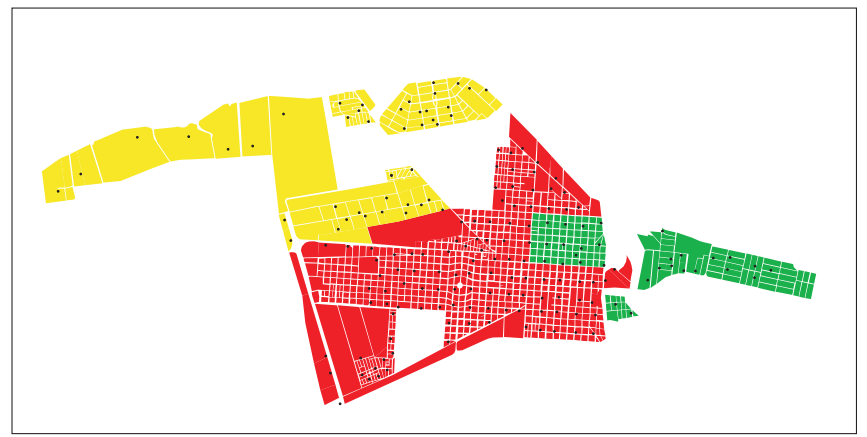

3b) Epidemiological week 8 to 11

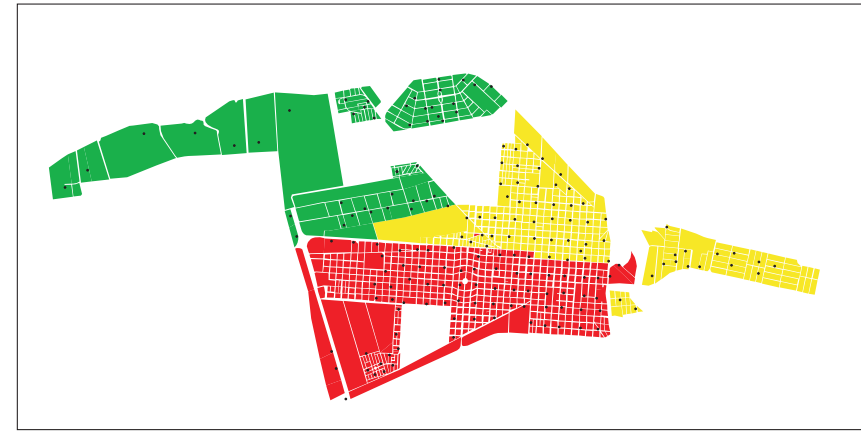

3d) Epidemiological week 10 to 13.

3c) Epidemiological week 9 to 12 .

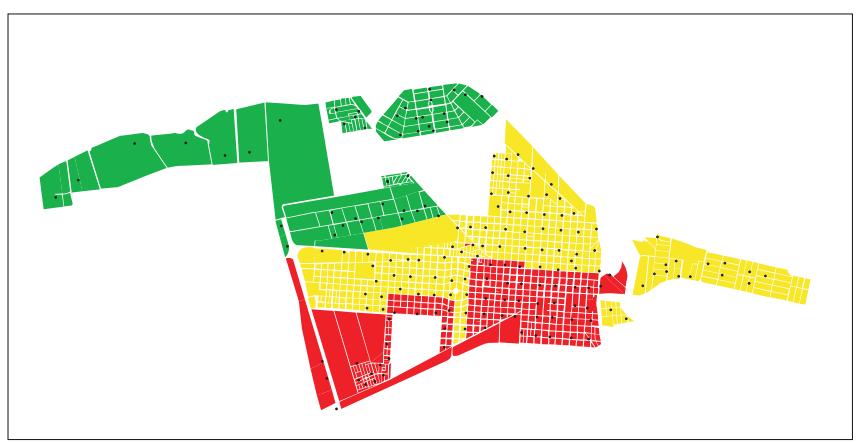

(continues)

MI-Dengue uses an electronic data recording system rather than paper spreadsheets, thus saving time and streamlining the processing of field results. Thus, by generating speedy, safe, weekly indices and maps that are absorbed into the municipal health service within 24 hours, furnishing seasonal vector data, MI-Dengue incorporates into the municipal dengue control programs the parameters that are needed to target and optimize Ae. aegypti control activities.

The advantages of MI-Dengue over conventional field data acquisition systems are: (a) immediate access to field data; (b) production of automatic entomological indices; and (c) organization and control of field inspectors' work (sites visited and scheduled for visits, visit times, trap locations, residents' names, etc.).
This technology's difficulties and limitations for monitoring infestation levels are related to the availability of MI-Dengue information technology equipment in the municipalities (e.g., computers, electronic spreadsheets, cell phones), Internet access, qualified human resources, and continuous quality control of field activities, like vector identification and management of field data collection. We observed that the municipalities that used both the MI-Dengue technology and the current National Dengue Control system experiences some difficulties in the two methods' joint implementation and consequently overloaded their available human resources. We thus suggest the following options: (a) increase the number of field personnel if the municipality chooses to use both methods or (b) 
3e) Epidemiological week 11 to 14 .

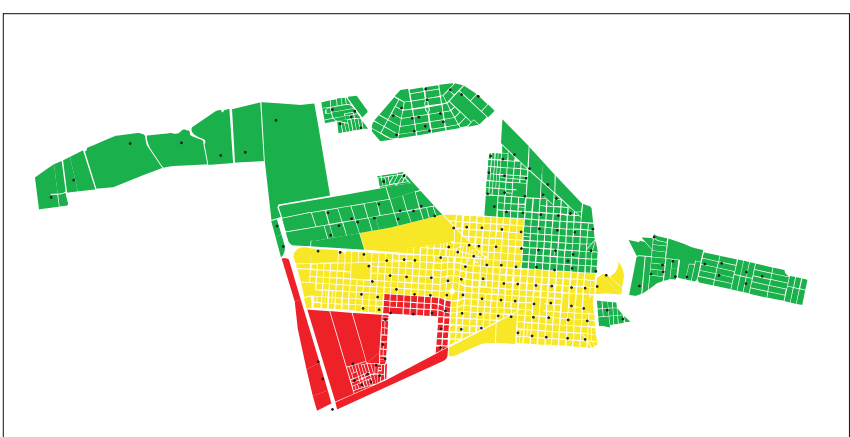

3g) Epidemiological week 13 to 16.

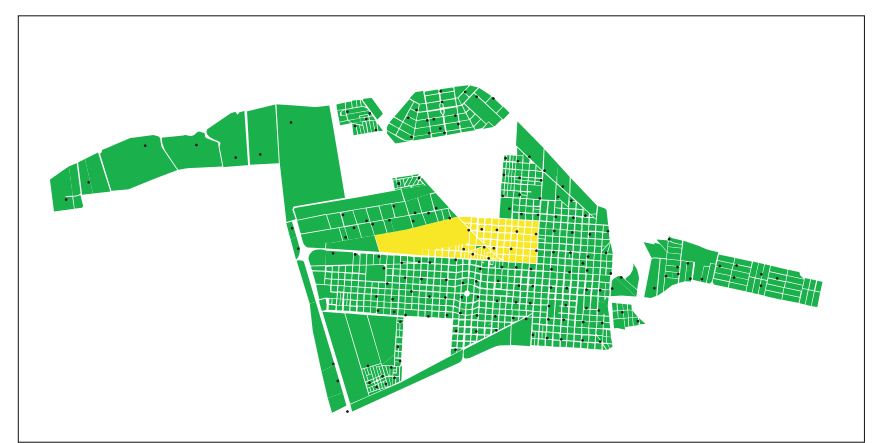

3f) Epidemiological week 12 to 15

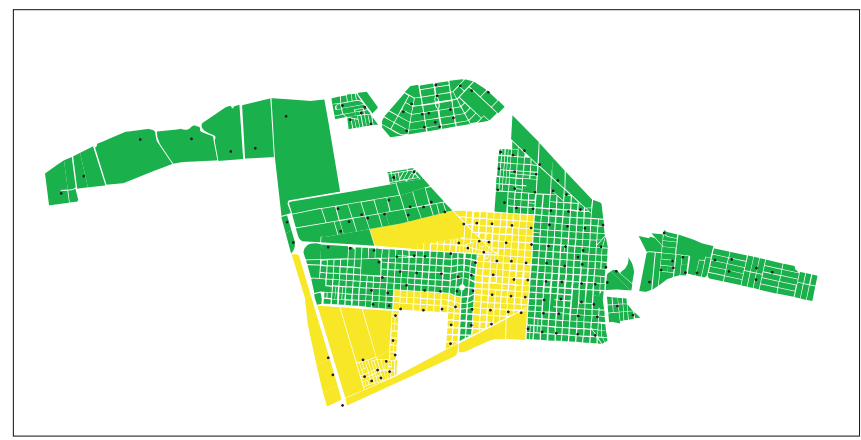

3h) Epidemiological week 14 to 17

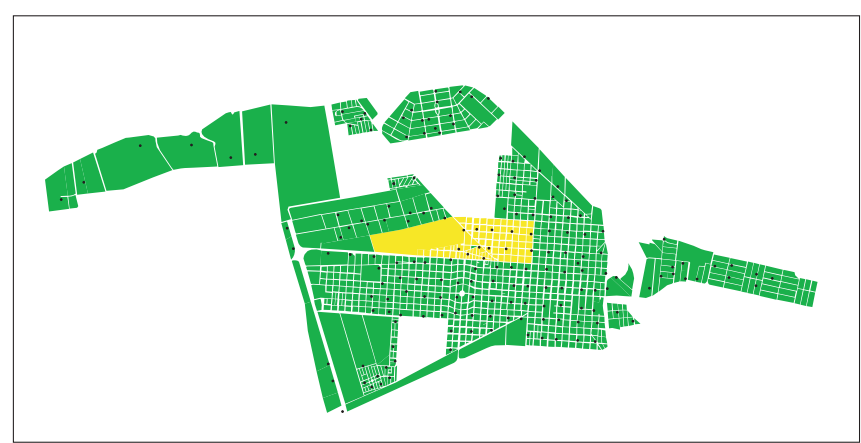

allow the municipality to opt for just one of the methodologies.

Monitoring gravid female Ae. aegypti with MosquiTRAP and MI-Dengue allowed the Municipal Health Secretariats to conduct weekly follow-up of infestation trends in neighborhoods and municipalities. These weekly data on infested sites and vector infestation levels incorporated important information into the municipal dengue control programs that assisted municipal health managers in targeting and optimizing their Ae. aegypti control activities.

The current study demonstrated the feasibility of MosquiTRAP and MI-Dengue under operational conditions for weekly monitoring of female adult Ae. aegypti in real time, as compared to other georeferenced studies that used sampling of immature forms of the mosquito 13,14,15,16,17,18 (eggs and larvae), which demand time and infrastructure for identification, quantification, and data processing. The georeferenced maps pro- duced by MI-Dengue and provided weekly on the Internet allowed municipal health managers to identify city blocks by colors (green, yellow, orange, and red) according to the number of female Ae. aegypti specimens captured. This information thus helped target activities to infested blocks in a 200-meter radius. This focal vector control strategy, supported by a weekly infestation monitoring system, allowed spatial localization of vector infestation and the evaluation of control measures within the radius represented by the trap.

Weekly analysis of Ae. aegypti neighborhood reinfestation in the previous four weeks helped managers to monitor the weekly situation with Ae. aegypti reinfestation in the municipality and visualize the evolution in control activities. This new procedure for rendering the MFAIt by categories and for classifying neighborhoods as "non-critical", "dengue alert", and "critical" facilitates, optimizes, and prioritizes the interventions 
Evolution in entomological indices in neighborhoods in the Municipality of Presidente Epitácio (São Paulo State, Brazil), classified according to temporal Mean Female Aedes Index (MFAlt) in the previous four epidemiological weeks.

\begin{tabular}{lccc}
\hline $\begin{array}{l}\text { Epidemiological weeks } \\
\text { Non-critical (MFAlt < 0.2) }\end{array}$ & $\begin{array}{c}\text { \% neighborhoods classified } \\
\text { Dengue Alert (0.2 < MFAlt < 0.4) }\end{array}$ & Critical (MFAlt > 0.4) \\
\hline 7 to 10 & 0.0 & 44.4 & 55.6 \\
8 to 11 & 22.2 & 33.3 & 44.4 \\
9 to 12 & 22.2 & 44.4 & 33.3 \\
10 to 13 & 22.2 & 66.7 & 11.1 \\
11 to 14 & 33.3 & 55.6 & 11.1 \\
12 to 15 & 66.7 & 33.3 & 0.0 \\
13 to 16 & 88.9 & 0.0 & 11.1 \\
14 to 17 & 88.9 & 11.1 & 0.0 \\
\hline
\end{tabular}

Table 3

Total autochthonous dengue cases and incidence in Municipalities that adopted MI-Dengue partially or fully and those that did not adopt the system.

\begin{tabular}{|c|c|c|c|c|c|c|c|c|c|c|}
\hline \multirow[t]{3}{*}{$\begin{array}{l}\text { Group of } \\
\text { Municipalities }\end{array}$} & \multirow[t]{3}{*}{ Municipality/State } & \multirow[t]{3}{*}{ Population } & \multicolumn{4}{|c|}{$\begin{array}{l}\text { Total dengue cases * (incidence per } \\
\qquad 100,000 \text { inhabitants) }\end{array}$} & \multicolumn{2}{|c|}{$\begin{array}{l}\text { Comparison with } \\
\text { incidence in } 1 \text { st } \\
\text { semester } 2007\end{array}$} & \multicolumn{2}{|c|}{$\begin{array}{l}\text { PNCD } \\
\text { Cycles }\end{array}$} \\
\hline & & & \multirow[t]{2}{*}{2006} & \multicolumn{2}{|c|}{2007} & \multirow{2}{*}{$\begin{array}{c}2008 \\
1 \mathrm{st} * \\
\text { semester }\end{array}$} & \multirow{2}{*}{$\begin{array}{c}2007 \\
\text { 2nd } \\
\text { semeste }\end{array}$} & \multirow{2}{*}{$\begin{array}{l}2008 \\
1 \text { st } \\
\text { emester }\end{array}$} & \multirow[t]{2}{*}{2007} & \multirow[t]{2}{*}{2008} \\
\hline & & & & $\begin{array}{c}1 \text { st } \\
\text { semester }\end{array}$ & $\begin{array}{c}\text { 2nd } \\
\text { semester }\end{array}$ & & & & & \\
\hline Partially adopted & Divinópolis/MG & 207,983 & $56(27)$ & $311(150)$ & $49(24)$ & $212(102)$ & -84.0 & -32.0 & 5 & 2 \\
\hline \multirow[t]{2}{*}{ MI-Dengue } & Pará de Minas/MG & 80,409 & $2(2)$ & $28(32)$ & $12(15)$ & $54(67)$ & -53.1 & 109.4 & 6 & 2 \\
\hline & Santa Luzia/MG & 214,398 & $62(29)$ & $111(52)$ & $23(11)$ & $198(92)$ & -78.8 & 76.9 & 5 & 2 \\
\hline Adopted & Três Lagoas/MS & 85,376 & $2,282(2,649)$ & $3,536(4,142)$ & $47(55)$ & $35(41)$ & -98.7 & -99.0 & 6 & 2 \\
\hline \multirow[t]{2}{*}{ MI-Dengue in full } & Presidente Epitácio/SP & 41,580 & $186(447)$ & $330(794)$ & $3(7)$ & 58 (139) & -99.1 & -82.5 & 4 & 2 \\
\hline & Bastos/SP & 21,343 & $4(19)$ & $582(2,727)$ & $7(33)$ & $2(9)$ & -98.8 & -99.7 & 6 & 2 \\
\hline Did not adopt & Andradina/SP & 54,794 & $513(936)$ & $2,792(5,095)$ & 70 (128) & $150(274)$ & -97.5 & -94.6 & 6 & 2 \\
\hline \multirow[t]{2}{*}{ MI-Dengue } & Presidente Venceslau/SP & 37,155 & $20(54)$ & $208(554)$ & $24(65)$ & $62(167)$ & -88.3 & -69.9 & 3 & 1 \\
\hline & Rancharia/SP & 23,337 & $5(21)$ & $206(883)$ & $24(103)$ & $32(137)$ & -88.3 & -84.5 & 4 & 1 \\
\hline
\end{tabular}

* Data available as of May 9, 2008.

MI-Dengue: Intelligent dengue monitoring; PNCD: National Dengue Control Program; MG: Minas Gerais State; MS: Mato Grosso do Sul State; SP: São Paulo State.

recommended by the dengue control program in the municipality.

Since 1994, dengue epidemics in Brazil have occurred mainly in the first half of the year 20 . The current study confirmed this same dengue epidemiological pattern in all the municipalities, regardless of the their groups. There are several variables that affect dengue transmission in a municipality 21,22,23,24 (e.g., environmental, social, seroprevalence, infected mosquitoes, population susceptibility to the dengue virus, vector control, etc.) and that can impact a dengue con- trol program. Based on our findings, the group of municipalities that only used the methodology recommended by the National Dengue Control Program showed varying responses, corroborating other studies in Brazil 21,24,25. The current study's preliminary findings suggest that the strategy that triggers interventions in cases of "dengue alert" and "critical" situations, with the adoption of control measures including houseto-house visits in a radius of $200 \mathrm{~m}$ from the positive trap, indicating that the MI-Dengue system helped reduce dengue cases in the municipali- 
ties that adopted it. Since the study period was short and the findings are preliminary (and may be subject to biases), further studies are needed to verify the reduction in dengue incidence based on activities oriented by the MI-Dengue system. For example, epidemiological data (seroprevalence and seroincidence) should be taken into consideration when evaluating the system.

The MosquiTRAP's characteristics are relevant for developing risk indices for dengue epidemics, based on the approach of capturing adult mosquitoes and furnishing entomological indices 4,5,6. In the current study, entomological indices were provided to municipal health managers to indicate the vector infestation sites and levels, thus prioritizing areas for vector control. However, we believe that an entomological index cannot be considered separately from other data to determine the risk of a dengue epidemic, which requires incorporating spatial and temporal data on the vector in the municipality, susceptibility of the human population to the virus, and mosquito infection rates.

Combined with weekly entomological diagnosis of the traps, the computerization of these procedures introduced advantages into the overall process, and the experience showed that these new innovative technological tools do not pose difficulties for learning how to use them or including them in the existing dengue control program. Finally, our findings indicate that new vector control strategies supported by the MosquiTRAP and the MI-dengue system represented important strides, and that the knowledge acquired from these experiences opens new channels for research on Ae. aegypti control.

\section{Resumo}

As limitações na identificação do Aedes aegypti em laboratório e no processamento das informações obtidas em campo pelo método da pesquisa larvária levaram ao desenvolvimento do "Monitoramento Inteligente da Dengue" (MI-Dengue). O MI-Dengue consiste em uma armadilha que captura fêmeas grávidas de Ae. aegypti associada ao sistema informatizado de coleta, transmissão e acesso das informações de campo, e mapas georreferenciados em tempo real. O objetivo deste trabalho foi descrever pela primeira vez um sistema de monitoramento de adultos de Ae. aegypti e apresentar os resultados preliminares em três municípios que adotaram o MI-Dengue como estratégia para identificar áreas e direcionar as ações de contro- le. Semanalmente, mapas georreferenciados e o indicador entomológico (IMFA) forneceram informações das áreas onde os niveis de infestações, caracterizados por cores em função da quantidade de fêmeas de Ae. aegypti capturadas, indicaram situação de sem risco, alerta e crítica que desencadearam ações de controle. Os resultados preliminares sugerem que a adoção dessa estratégia de controle com visitas casa a casa em um raio de 200m da armadilha positiva contribuiu para a redução de casos de dengue nos municípios que adotaram o MI-Dengue.

Dengue; Controle de Vetores; Monitoramento; Análise Espacial 


\section{Contributors}

A. E. Eiras organized the article as a whole and analyses of the results; conducted the literature review; and was responsible for writing and submitting the manuscript. M. C. Resende assisted in the literature review, analyses, and writing of the manuscript.

\section{Acknowledgments}

The authors wish to thank the Service for Support to Micro and Small Businesses (SEBRAE), the Funding Agency for Studies and Projects (FINEP), the Minas Gerais State Research Foundation (FAPEMIG), and the Brazilian National Research Council (CNPq) for their support in the development of the MosquiTRAP, Dr. Fabiano Pimenta (Health Surveillance Secretariat, Brazilian Ministry of Health) for encouraging the implementation of MIDengue in the State of Minas Gerais, the Municipalities that kindly provided the current data on autochthonous dengue cases, the technical staff of Ecovec Ltda. for providing the databank on vector monitoring, Luciano Rios Scherrer for the statistical analyses, and Dr. Maria da Glória Teixeira for her suggestions during revision of the manuscript.

\section{References}

1. Barbosa-da-Silva Jr. J, Siqueira Jr. JB, Coelho GE, Vilarinhos PT, Pimenta Jr. FG. Dengue in Brazil: current situation and control activities. Epidemiol Bull 2002; 23:3-6.

2. Gubler DJ. Dengue and dengue hemorrhagic fever: its history and resurgence as a global health problem. In: Gubler DJ, Kuno G, editors. Dengue and dengue hemorrhagic fever. New York: CAB International; 1997. p. 1-22.

3. Fundação Nacional de Saúde. Dengue. Instrução para pessoal de combate ao vetor: manual de normas técnicas. 3a Ed. Brasília: Ministério da Saúde/Fundação Nacional da Saúde; 2001.

4. Focks DA. A review of entomological sampling methods and indicators for dengue vectors. Geneva: World Health Organization; 2003. (Document WHO/TDR/IDE/Den/03.1).

5. Gomes AC. Medidas dos níveis de infestação urbana para Aedes (Stegomyia) aegypti e Aedes (Stegomyia) albopictus em programa de vigilância entomológica. Inf Epidemiol SUS 1998; 7:49-57.
6. Ritchie SA, Long S, Smith G, Pike A, Knox TB. Entomological investigations in a focus of Dengue transmission in Cairns, Queensland, Australia, by using the sticky ovitraps. J Med Entomol 2004; 41:1-4.

7. Braga IA, Gomes AC, Nelson M, Mello RCG, Bergamaschi DP, Souza JMP. Comparação entre pesquisa larvária e armadilha de oviposição, para detecção de A. aegypti . Rev Soc Bras Med Trop 2000; 33: 347-53.

8. Gama RA, Silva EM, Silva IM, Resende MC, Eiras AE. Evaluation of the sticky MosquiTRAPTM for detecting Aedes (Stegomyia) aegypti (L.) (Diptera: Culicidae) during the dry season in Belo Horizonte, Minas Gerais, Brazil. Neotrop Entomol 2007; 36: 294-302.

9. Maciel-de-Freitas RM, Eiras AE, Lourenço-deOliveira R. Field evaluation of effectiveness of the BG-Sentinel, a new trap for capturing adult Aedes aegypti (Diptera: Culicidae). Mem Inst Oswaldo Cruz 2006; 101:321-5. 
10. Fávaro EA, Mondini A, Dibo MR, Barbosa AAC, Eiras AE. Assessment of entomological indicators of Aedes aegypti (L.) from adult and egg collections in São Paulo, Brazil. J Vector Ecol 2008; 33:8-16.

11. Favaro EA, Dibo MR, Mondini A, Eiras AE. Physiological state of Aedes (Stegomyia) aegypti mosquitoes captured with MosquiTRAPs in Mirassol, São Paulo, Brazil. J Vector Ecol 2006; 31:285-91.

12. Maciel-de-Freitas R, Eiras AE, Lourenço-de-Oliveira $\mathrm{R}$. Calculating the survival rate and estimated population density of gravid Aedes aegypti (Diptera, Culicidae) in Rio de Janeiro, Brazil. Cad Saúde Pública 2008; 24:2747-54.

13. Dale PER, Ritchie SA, Territo BM, Morris CD, Muhar A, Kay BH. An overview of remote sensing and GIS for surveillance of mosquito vector habitats and risk assessment. J Vector Ecol 1998; 23:54-61.

14. Spradling SL, Olson JK, Coulson RN, Lovelady CN. A geographic information system approach to evaluating the effects of the endangered species protection program on mosquito control. J Am Mosq Control Assoc 1998; 14:137-47.

15. Chansang C, Kittayapong P. Application of mosquito sampling count and geospatial methods to improve dengue vector surveillance. Am J Trop Med Hyg 2007; 77:897-902.

16. Lagrotta MT, Silva WC, Santos RS. Identification of key areas for Aedes aegypti control through geoprocessing in Nova Iguaçu, Rio de Janeiro State, Brazil. Cad Saúde Pública 2008; 24:70-80.

17. Lêda R, Monteiro AM, Melo-Santos MAV, Silveira Jr. JC. Developing new approaches for detecting and preventing Aedes aegypti population outbreaks: basis for surveillance, alert and control system. Mem Inst Oswaldo Cruz 2008; 103:50-9.
18. Ai-leen GT, Song RJ. The use of GIS in ovitrap monitoring for dengue control in Singapore. Dengue Bull 2000; 24:110-6.

19. Fundação Nacional de Saúde, Ministério da Saúde. Plano Nacional de Controle da Dengue. Brasília: Fundação nacional de Saúde, Ministério da Saúde; 2002.

20. Siqueira JB, Martinelli MCT, Coelho GE, Simplício AMR, Hatch LD. Dengue and dengue hemorrhagic fever, Brazil, 1981-2002. Emerg Infect Dis 2005; 11:48-53.

21. Barata EAMF, Costa AIP, Chiaravalloti-Neto F, Glasser CM, Barata JMS, Natal D. População de A. aegypti (L) em área endêmica de dengue, sudeste do Brasil. Rev Saúde Pública 2001; 35:237-42.

22. Mondini A, Chiaravalloti- Neto F. Variáveis socioeconômicas e a transmissão de dengue. Rev Saúde Pública 2007; 41:923-30.

23. Teixeira MG, Costa MCN, Barreto ML, Mota E. Dengue and dengue hemorrhagic fever epidemics in Brazil: what research is needed based on trends, surveillance and control experiences? Cad Saúde Pública 2005; 21:1307-15.

24. Mondini A, Chiaravalloti Neto F, Sanches MG, Lopes JCC. Análise espacial da transmissão de dengue em cidade de porte médio do interior paulista. Rev Saúde Pública 2005; 39:444-51.

25. Corrêa PRL, França E, Bogutchi TF. Infestação pe lo Aedes aegypti e ocorrência da dengue em Belo Horizonte, Minas Gerais. Rev Saúde Pública 2005; 39:33-40.

Submitted on 09/Jun/2008

Final version resubmitted on 10/Oct/2008

Approved on 29/Oct/2008 